\title{
Twenty-Four Hour Tonometry in Patients Suspected of Chronic Gastrointestinal Ischemia
}

\author{
Peter B. F. Mensink • Robert H. Geelkerken • \\ Ad B. Huisman · Ernst J. Kuipers · Jeroen J. Kolkman
}

Received: 22 February 2007 / Accepted: 22 March 2007/Published online: 26 May 2007

(C) Springer Science+Business Media, LLC 2007

\begin{abstract}
Background and aims Gastrointestinal tonometry is currently the only clinical diagnostic test that enables identification of symptomatic chronic gastrointestinal ischemia. Gastric exercise tonometry has proven its value for detection of ischemia in this patients group, but has its disadvantages. Earlier studies with postprandial tonometry gave unreliable results. In this study we challenged (again) the use of postprandial tonometry in patients suspected of gastrointestinal ischemia.

Methods Patients suspected for chronic gastrointestinal ischemia had standard diagnostic work up, including gastric exercise tonometry and 24-h tonometry using standard meals.

Results Thirty-three patients were enrolled in the study. Chronic gastrointestinal ischemia was diagnosed in 17
\end{abstract}

P. B. F. Mensink ( $\square)$

Department of Gastroenterology and Hepatology, Erasmus MC University Medical Center, s-Gravendijkwal 230, 3015 CE

Rotterdam, The Netherlands

e-mail: p.mensink@erasmusmc.nl

R. H. Geelkerken

Department of Vascular Surgery, Medisch Spectrum Twente, Enschede, The Netherlands

\section{A. B. Huisman}

Department of Interventional Radiology, Medisch Spectrum

Twente, Enschede, The Netherlands

\section{E. J. Kuipers}

Department of Gastroenterology and Hepatology, Erasmus MC University Medical Center, Rotterdam, The Netherlands

\section{J. J. Kolkman}

Department of Internal Medicine and Gastroenterology, Medisch Spectrum Twente, Enschede, The Netherlands
(52\%) patients. The 24-h tonometry correctly predicted the presence of ischemia in 13/17 patients, and absence of ischemia in $15 / 16$ patients.

Conclusions The use of 24-h tonometry after meals in patients suspected of gastrointestinal ischemia seems feasible, with promising accuracy for the detection of ischemia.

Keywords Chronic splanchnic syndrome - Chronic mesenteric ischemia $\cdot$ Splanchnic stenosis $\cdot$ Carbon dioxide Gastric tonometry $\cdot$ Small bowel tonometry

\section{Introduction}

In patients presenting with postprandial pain, especially when associated with weight loss and positive history for cardiovascular diseases, chronic gastrointestinal ischemia (CGI) should be among the differential diagnosis [1-3]. Vascular anatomic abnormalities can be demonstrated with duplex ultrasound or angiography. However, a stenosis does not necessarily imply ischemia, due to the abundant collateral circulation. We have recently demonstrated that gastric exercise tonometry (GET) allows differentiation between patients with and without gastrointestinal ischemia. GET showed an accuracy of $87 \%$ in detection of gastrointestinal ischemia. The patients selected for treatment using GET, are likely to benefit from revascularization techniques [4-9].

Gastric (exercise) tonometry is not widely accepted as a diagnostic technique for gastrointestinal ischemia due to the lack of familiarity with this approach and its timeconsuming nature. Twenty-four hour gastrointestinal tonometry with meals is more familiar (resembling 24-h pH measurement) and easier to perform. Over $90 \%$ of CGI 
patients report postprandial, while only $60 \%$ report exercise-related, complaints. Ischemic pain after meals in CGI is caused by insufficient increase of postprandial blood flow to balance the increased metabolic demand of the gastrointestinal tract [10]. This indicates that tonometry directly after meals would be the most physiologic approach of measuring ischemia in these patients. However, earlier studies showed unreliable results using tonometry after meals, related to insufficient suppression of gastric acid secretion and dilution effects [11-13]. We therefore started by testing standard meals in vitro and performed a study with healthy subjects using these meals and highdose proton pump inhibition (PPI) as an optimal gastric acid suppressant [14]. In this study we retrospectively evaluated the additional value of prolonged gastrointestinal tonometry in a group of patients suspected for possible CGI.

\section{Methods}

Patients with unexplained chronic abdominal symptoms who were referred for suspected CGI were included in this study. More-common causes of chronic abdominal symptoms had been excluded previously by appropriate diagnostic evaluation. All patients had imaging of the splanchnic arteries [intra-arterial digital substraction multiplane abdominal angiography (DSA) and duplex ultrasound scanning] and GET. Along with this standard diagnostic work up, patients had twenty-four hour $(24 \mathrm{~h})$ tonometry testing, directly following GET.

\section{Gastric exercise tonometry (GET)}

GET was performed using a standardized protocol, before, during, and after $10 \mathrm{~min}$ of submaximal exercise, as described previously with both gastric and jejunal catheters [15]. A maximal gradient was calculated between stomach and arterial $\mathrm{PCO}_{2}$. The criteria for a positive GET (all three required), established in healthy volunteers and a patient cohort, were: (1) a gradient of $>0.8 \mathrm{kPa}$ in the stomach after exercise, (2) an increase in gastric $\mathrm{PCO}_{2}$, and (3) an arterial lactate $<8 \mathrm{mmol} / \mathrm{l}[8,15]$.
Twenty-four hour tonometry testing

A gastric and jejunal tonometer catheter (8 French, Datex Ohmeda, Helsinki, Finland) and a gastric $\mathrm{pH}$ meter (pHersaflexTM, internal reference, Medical Measurement Systems, Enschede, the Netherlands) were inserted nasogastrically using fluoroscopy. Intravenous infusion of omeprazole was started with a bolus of $80 \mathrm{mg}$ in $30 \mathrm{~min}$, followed by $8 \mathrm{mg} / \mathrm{h}$, using an infusion pump (Perfusor compact $^{\circledR}$, B Braun Melsungen AG, Melsungen, Germany). The catheters were connected, respectively, to the Tonocap (Datex Ohmeda, Helsinki, Finland) and the pH recording device (Medical Measurement Systems, Enschede, the Netherlands). The Tonocaps were connected to a computer on which a data-collection program automatically registered the gastric and jejunal $\mathrm{PCO}_{2}$ level every $10 \mathrm{~min}$. The gastric $\mathrm{pH}$ was automatically recorded and stored in a datalogger (Medical Measurement Systems, Enschede, the Netherlands), which also allows for realtime reading of the gastric $\mathrm{pH}$.

As soon as the gastric $\mathrm{pH}$ was $>4.0$ for $\geq 30 \mathrm{~min}$, the first meal was started $(t=0 \mathrm{~min})$. All patients had meals at standard times: breakfast I (08:00), dinner (12:00), liquid compound meal I (15:00), bread meal (18:00), liquid compound meal II (21:00), and breakfast II (08:00 the next day). The breakfast, bread, and dinner meals were standardized. The liquid compound meal consisted of two packages of $200 \mathrm{ml}$ each (Nutridrink ${ }^{\circledR}$, Nutricia, The Netherlands). The contents and caloric density of each meal used are presented in Table 1 . The patients were instructed to eat their meals within $15 \mathrm{~min}$. The consumption of small amounts of liquids (noncarbonated) was allowed and noted, consumption of alcohol-, acid-, and $\mathrm{CO}_{2}$-containing beverages was strictly prohibited. Due to the limited length of the catheters, the subjects were only capable of performing very minor exercise and were allowed to lie down in supine position from 22:00.

\section{Diagnosis and treatment}

The results of all diagnostic procedures were discussed in a multidisciplinary team. In this team a gastroenterologist, a vascular surgeon, and an interventional radiologist

Table 1 Composition characteristics of the various standard meals

\begin{tabular}{lll}
\hline Meal & Composition & $\mathrm{kcal} / \mathrm{g}$ \\
\hline Breakfast & Fat (16\%), proteins (22\%), carbohydrates (62\%) & 1.7 \\
Dinner & Fat (16\%), proteins (47\%), carbohydrates (37\%) & 2.2 \\
Bread meal & Fat (10\%), proteins (19\%), carbohydrates (71\%) & 1.8 \\
Compound solution & Fat (35\%), proteins (16\%), carbohydrates (49\%) & 1.5 \\
\hline
\end{tabular}

Percentages of delivered energy $($ En\% $)$; $\mathrm{kcal}=$ kilocalories; $\mathrm{g}=$ gram. 
discussed the symptoms, medical history, physical examination, and all diagnostic evaluations, with the exception of the results on 24-h tonometry. The latter therefore did not influence the consensus diagnosis. The multidisciplinary team decided for every patient: (1) no splanchnic stenosis, (2) splanchnic stenosis and no ischemia or (3) splanchnic stenosis and ischemia (i.e. chronic gastrointestinal ischemia, CGI). The gold standard for the diagnosis of chronic gastrointestinal ischemia was a positive outcome after successful revascularization at (long-term) follow-up. The outcome of GET, and consensus diagnosis of the multidisciplinary team were compared to the results of the 24-h tonometry testing.

Definition of a positive (abnormal) $24 \mathrm{~h}$ tonometry

The cut-off values established in the previous healthy subjects study were used to define the criteria for the results on 24-h tonometry [9]. These cut-off values were, for the stomach: 12.1, 11.4, and $11.3 \mathrm{kPa}$ for the breakfast (or bread meal), dinner, and compound solution meals, respectively; in the jejunum these threshold values were, respectively, 12.0, 13.6, and $10.6 \mathrm{kPa}$. The criteria for a positive finding (abnormal result) on 24-h tonometry were: (1) pathologic responses after three or more (standard) meals, or (2) a combination of one or two pathologic responses after (standard) meals combined with a median $\mathrm{PCO}_{2}>8.0 \mathrm{kPa}$, measured in between meals.

\section{Statistics}

Data were expressed as mean (standard deviation) or median (range) when appropriate. The data of the ischemic and non-ischemic patients were compared using Student's $t$-test or $\chi^{2}$ testing. Sensitivity, specificity as well as positive and negative predicted values of 24-h tonometry were calculated with the consensus diagnosis as the gold standard.

\section{Results}

Patient characteristics

In a period of three years (2002-2005), in 37 patients referred for suspected of CGI, 24-h tonometry along with the standard work-up was performed. Of these, 33 (89\%) patients had complete work-up and were included in this study. Mean age was 54 (22-82) years, with eight males and 25 females. Significant splanchnic stenosis were found in $23 / 33(69 \%)$ patients. A significant single vessel splanchnic stenosis was found in 14/33 (42\%) patients [13 celiac artery (CA) and one superior mesenteric artery
(SMA)]. A significant stenosis of two splanchnic arteries was found in 9/33 (27\%) patients (all CA and SMA stenosis).

All 33 patients had chronic abdominal pain for a mean of 35 months (range 3-120), 24/33 (73\%) patients had pain following meals, 11/33 (33\%) patients reported pain during or after exercise, 9/33 (27\%) patients reported both pain following meals and during, or after, exercise, and 23/33 (70\%) patients reported weight loss. The mean weight loss was $11 \mathrm{~kg}$ (range $3-28 \mathrm{~kg}$ ) in 17 months (range 2120 months); see Table 1.

Gastric exercise tonometry

In $18 / 31(58 \%)$ patients a gradient of $>0.8$ was found by GET. In 14/18 (78\%) patients this increased gradient was defined as abnormal using the three criteria as previously defined. In four patients a gradient $>0.8 \mathrm{kPa}$ was not caused by ischemia: three patients had persistent acid production, and one performed excessive exercise (leading to false positive findings) [8].

Consensus diagnosis of the multidisciplinary team and results after treatment

According to the team the diagnosis of no stenosis (and no ischemia), stenosis but no ischemia, and stenosis with ischemia (CGI) was diagnosed in, respectively, 12 (36\%), four $(12 \%)$ and $17(52 \%)$ patients.

Fifteen patients diagnosed with CGI had treatment: 10 patients surgical and five patients stent-placement therapy. Three patients had no treatment: two patients preferred a conservative approach and one patient proved inoperable due to comorbidity. After a mean follow-up of 55 months (49-85), 12 out of 15 (80\%) patients were free of complaints, one patient died immediately after surgical revascularization (multiple organ failure), one patient had partial improvement, and one patient had persistent complaints. The latter patient had a celiac artery release, and was diagnosed as having no CGI after follow-up; this patient had no abnormalities on 24-h tonometry testing; see Table 2.

\section{Twenty-four hour tonometry}

The 24-h tonometry was well tolerated in all patients, no medical or technical problems occurred. In 28/33 (85\%) patients tonometric measurements were performed in both stomach and jejunum, in 5/33 (15\%) patients only stomach measurements were performed (in all five patients placement of jejunal tonometry catheter failed); see Fig. 1. In 8/ $33(24 \%)$ patients a dose reduction of the compound solution was necessary, due to patient's inability to 
Table 2 Patient characteristics, results of diagnostic tests and conclusion

\begin{tabular}{|c|c|c|c|c|c|c|c|c|c|c|c|}
\hline $\mathrm{Nr}$ & Age & Sex & Stenosis & $\begin{array}{l}\mathrm{PP} \\
\text { pain }\end{array}$ & $\begin{array}{l}\mathrm{PE} \\
\text { pain }\end{array}$ & $\begin{array}{l}\text { GET } \\
\text { results }\end{array}$ & $\begin{array}{l}\text { Consensus } \\
\text { diagnosis }\end{array}$ & Treatment & $\begin{array}{l}\text { Outcome } \\
\text { complaints }\end{array}$ & Final conclusion & $\begin{array}{l}\text { 24-h tono } \\
\text { results }\end{array}$ \\
\hline 1 & 61 & $\mathrm{~F}$ & None & + & - & 0,5 & $\begin{array}{l}\text { No stenosis, no } \\
\text { ischemia }\end{array}$ & - & & $\begin{array}{l}\text { No stenosis, no } \\
\text { ischemia }\end{array}$ & Normal \\
\hline 2 & 36 & $\mathrm{M}$ & $\mathrm{CA}$ & + & - & 0,4 & No ischemia & - & & No ischemia & Normal \\
\hline 3 & 55 & $\mathrm{~F}$ & $\mathrm{CA}$ & + & - & $0,7^{\mathrm{a}}$ & CGI & Surgery & Free & CGI & Abnormal \\
\hline 4 & 76 & M & None & - & - & 0,6 & $\begin{array}{l}\text { No stenosis, no } \\
\text { ischemia }\end{array}$ & - & & $\begin{array}{l}\text { No stenosis, no } \\
\text { ischemia }\end{array}$ & Normal \\
\hline 5 & 47 & M & None & - & + & $1,6^{\mathrm{b}}$ & $\begin{array}{l}\text { No stenosis, no } \\
\text { ischemia }\end{array}$ & - & & $\begin{array}{l}\text { No stenosis, no } \\
\text { ischemia }\end{array}$ & Normal \\
\hline 6 & 42 & $\mathrm{~F}$ & $\mathrm{CA}+\mathrm{SMA}$ & - & - & 1,5 & CGI & Surgery & Free & CGI & Abnormal \\
\hline 7 & 65 & $\mathrm{~F}$ & $\mathrm{CA}+\mathrm{SMA}$ & - & - & 2,0 & CGI & Conservative & & CGI & Abnormal \\
\hline 8 & 77 & $\mathrm{~F}$ & $\mathrm{CA}+\mathrm{SMA}$ & + & - & 2,2 & CGI & Surgery & Died post-op. & CGI & Abnormal \\
\hline 9 & 72 & $\mathrm{~F}$ & SMA & + & + & 1,8 & CGI & Stent & Free & CGI & Abnormal \\
\hline 10 & 41 & M & None & + & - & $2,8^{\mathrm{c}}$ & $\begin{array}{l}\text { No stenosis, no } \\
\text { ischemia }\end{array}$ & - & & $\begin{array}{l}\text { No stenosis, no } \\
\text { ischemia }\end{array}$ & Normal \\
\hline 11 & 72 & $\mathrm{~F}$ & CA & + & - & 1,4 & CGI & Stent & Partial relieve & CGI & Abnormal \\
\hline 12 & 67 & $\mathrm{~F}$ & $\mathrm{CA}$ & - & - & $0,9^{\mathrm{c}}$ & $\begin{array}{l}\text { No stenosis, no } \\
\text { ischemia }\end{array}$ & - & & No ischemia & Normal \\
\hline 13 & 40 & $\mathrm{~F}$ & $\mathrm{CA}$ & - & + & $1,1^{\mathrm{c}}$ & CGI & Surgery & Unchanged & No ischemia & Normal \\
\hline 14 & 82 & M & $\mathrm{CA}+\mathrm{SMA}$ & + & + & 1,0 & CGI & Conservative & & CGI & Normal \\
\hline 15 & 54 & $\mathrm{~F}$ & $\mathrm{CA}$ & + & + & 0,9 & CGI & Conservative & & CGI & Normal \\
\hline 16 & 26 & M & $\mathrm{CA}$ & + & + & 1,0 & CGI & Surgery & Free & CGI & Abnormal \\
\hline 17 & 58 & M & None & + & + & $2,2^{\mathrm{c}}$ & $\begin{array}{l}\text { No stenosis, no } \\
\text { ischemia }\end{array}$ & - & & $\begin{array}{l}\text { No stenosis, no } \\
\text { ischemia }\end{array}$ & Normal \\
\hline 18 & 22 & $\mathrm{~F}$ & CA & + & - & 0,7 & No ischemia & - & & No ischemia & Normal \\
\hline 19 & 42 & $\mathrm{~F}$ & None & + & - & $1,1^{\mathrm{d}}$ & $\begin{array}{l}\text { No stenosis, no } \\
\text { ischemia }\end{array}$ & - & & $\begin{array}{l}\text { No stenosis, no } \\
\text { ischemia }\end{array}$ & Normal \\
\hline 20 & 48 & $\mathrm{~F}$ & $\mathrm{CA}$ & + & - & 1,7 & CGI & Surgery & Free & CGI & Normal \\
\hline 21 & 51 & $\mathrm{~F}$ & $\mathrm{CA}$ & + & - & 0,7 & No ischemia & - & & No ischemia & Normal \\
\hline 22 & 43 & $\mathrm{~F}$ & $\mathrm{CA}+\mathrm{SMA}$ & + & + & $0,5^{\mathrm{e}}$ & CGI & Surgery & Free & CGI & Abnormal \\
\hline 23 & 54 & $\mathrm{~F}$ & $\mathrm{CA}+\mathrm{SMA}$ & - & - & 1,5 & CGI & Surgery & Free & CGI & Normal \\
\hline 24 & 76 & $\mathrm{~F}$ & $\mathrm{CA}+\mathrm{SMA}$ & + & - & $0,6^{\mathrm{f}}$ & CGI & Stent & Free & CGI & Abnormal \\
\hline 25 & 53 & $\mathrm{M}$ & None & + & - & $2,0^{\mathrm{c}}$ & $\begin{array}{l}\text { No stenosis, no } \\
\text { ischemia }\end{array}$ & - & & $\begin{array}{l}\text { No stenosis, no } \\
\text { ischemia }\end{array}$ & Normal \\
\hline 26 & 53 & $\mathrm{~F}$ & $\mathrm{CA}$ & + & + & 1,1 & CGI & Stent & Free & CGI & Abnormal \\
\hline 27 & 50 & $\mathrm{~F}$ & $\mathrm{CA}$ & - & - & 1,3 & CGI & Surgery & Free & CGI & Abnormal \\
\hline 28 & 61 & $\mathrm{~F}$ & $\mathrm{CA}+\mathrm{SMA}$ & + & + & 1,7 & CGI & Stent & Free & CGI & Abnormal \\
\hline 29 & 63 & $\mathrm{~F}$ & None & + & - & 0,8 & $\begin{array}{l}\text { No stenosis, no } \\
\text { ischemia }\end{array}$ & - & & $\begin{array}{l}\text { No stenosis, no } \\
\text { ischemia }\end{array}$ & Normal \\
\hline 30 & 24 & $\mathrm{~F}$ & $\mathrm{CA}$ & + & + & 1,3 & CGI & Surgery & Free & CGI & Abnormal \\
\hline 31 & 74 & $\mathrm{~F}$ & $\mathrm{CA}+\mathrm{SMA}$ & - & - & 0,8 & No ischemia & - & & No ischemia & Normal \\
\hline 32 & 41 & $\mathrm{~F}$ & None & + & - & $1,2^{\mathrm{d}}$ & $\begin{array}{l}\text { No stenosis, no } \\
\text { ischemia }\end{array}$ & - & & $\begin{array}{l}\text { No stenosis, no } \\
\text { ischemia }\end{array}$ & Normal \\
\hline 33 & 63 & $\mathrm{~F}$ & None & + & - & 0,0 & $\begin{array}{l}\text { No stenosis, no } \\
\text { ischemia }\end{array}$ & - & & $\begin{array}{l}\text { No stenosis, no } \\
\text { ischemia }\end{array}$ & Abnormal \\
\hline
\end{tabular}

$\mathrm{PP}=$ postprandial, $\mathrm{PE}=$ post-exercise, $\mathrm{M}=$ male, $\mathrm{F}=$ female $; \mathrm{CA}=$ celiac artery, $\mathrm{SMA}=$ superior mesenteric artery; GET = gastric exercise tonometry, result presented as gradient (in $\mathrm{kPa}$ ); 24-h tono = twenty-four hour tonometry; CGI = chronic gastrointestinal ischemia.

a false negative GET

b acid production during GET

c false positive GET

d no $\mathrm{CO}_{2}$ raise during GET

e abnormal jejunal gradient during GET

f minor exercise during GET 
Fig. 1 Individual curves of results of 24-h tonometry in a non-ischemic (A) and an ischemic patient (B). Individual curves of a non-ischemic patient (A) and an chronic gastrointestinal ischemia patient (B); on the horizontal axis the time from 0 to $24 \mathrm{~h}$, on the vertical axis $\mathrm{PCO}_{2}$ from 0 to 20 in kilopascal $(\mathrm{kPa})$; curves: $\mathrm{PCO}_{2}$ values measured every $10 \mathrm{~min}$ in $\operatorname{stomach}(\square)$, jejunum $(X)$ and four meals spread over the $24 \mathrm{~h}$ period (*)

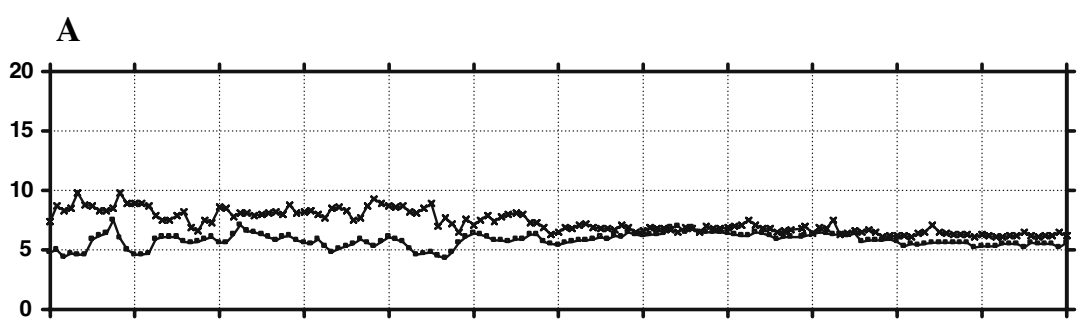

B

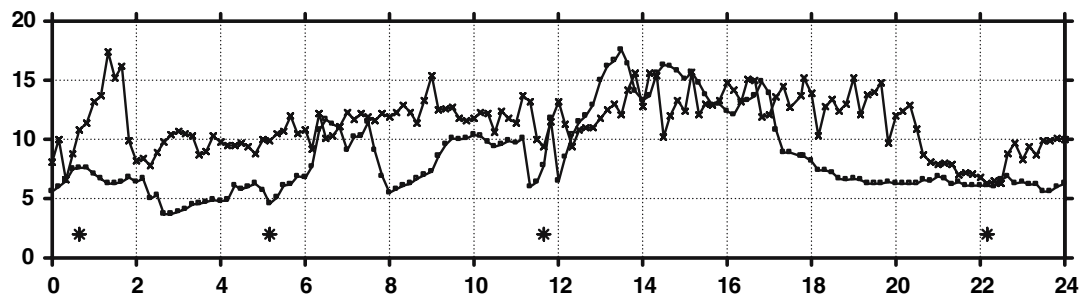

consume the normal dosage. The overall gastric acid suppression was good, with a gastric $\mathrm{pH}>4$ during $94.8 \%$ (range 71-100\%) of the time. Pathological peaks during 24-h tonometry coexisting with periods of $\mathrm{pH}<4$, were defined as non-pathologic peaks.

The fasting baseline of stomach and jejunal $\mathrm{PCO}_{2}$ measurements were significantly higher in the ischemic patients compared to the non-ischemic patients group. The jejunal $\mathrm{PCO}_{2}$ peaks after breakfast and dinner were significantly higher in the ischemic patients compared to the non-ischemic patients; see Tables 3 and 4.

Using the previously defined criteria, 13/17 patients with CGI and 15/16 patients without ischemia were correctly identified with $24-\mathrm{h}$ tonometry. The calculated test properties show a sensitivity of $76 \%$ and a specificity of $94 \%$, a positive predictive value (PPV) of $76 \%$ and a negative predictive value (NPV) of $94 \%$ for detection of ischemia by 24-h tonometry alone. Combining the results of GET and 24-h tonometry, 17/17 patients with CGI and 16/16 patients without ischemia could be correctly identified (sensitivity of $100 \%$ and specificity of $100 \%$ ).

Comparing patients with single- and multi-vessel ischemia, or patients with or without postprandial and/or exercise-related complaints, no significant differences in diagnostic accuracy were found.

Table 3 Results of 24-h tonometry in ischemic and non-ischemic patients

\begin{tabular}{|c|c|c|c|c|c|c|}
\hline & \multicolumn{3}{|l|}{ CGI pts. } & \multicolumn{3}{|c|}{ Non-ischemic pts. } \\
\hline & Peak & $\Delta$-peak & Mean $\mathrm{PCO}_{2}$ & Peak & $\Delta$-peak & Mean $\mathrm{PCO}_{2}$ \\
\hline \multicolumn{7}{|l|}{ Stomach } \\
\hline B & $10.6(3.9)$ & $4.0(3.4)$ & - & $8.5(2.7)$ & $2.6(2.0)$ & - \\
\hline D & $9.9(1.9)$ & $3.7(1.5)$ & - & $8.5(2.3)$ & $3.3(2.5)$ & - \\
\hline $\mathrm{CS}$ & $10.4(3.0)$ & $3.3(2.2)$ & - & $8.1(2.6)$ & $1.8(1.2)$ & - \\
\hline Fasting & - & - & $7.7(1.4)^{\mathrm{a}}$ & - & - & $6.8(0.7)$ \\
\hline Day & - & - & $6.9(1.1)$ & - & - & $6.5(0.7)$ \\
\hline Night & - & - & $8.2(1.8)$ & - & - & $6.9(0.8)$ \\
\hline \multicolumn{7}{|l|}{ Jejunum } \\
\hline B & $11.6(3.2)^{\mathrm{b}}$ & $3.2(1.5)$ & - & $8.8(1.4)$ & $2.1(0.8)$ & - \\
\hline $\mathrm{D}$ & $12.2(3.4)^{\mathrm{c}}$ & $3.7(2.0)$ & - & $9.0(1.7)$ & $2.2(0.7)$ & - \\
\hline $\mathrm{CS}$ & $10.6(2.2)$ & $2.5(1.6)$ & - & $9.0(1.9)$ & $1.5(1.0)$ & - \\
\hline Fasting & - & - & $8.9(1.6)^{\mathrm{d}}$ & - & - & $7.4(0.7)$ \\
\hline Day & - & - & $8.8(1.3)$ & - & - & $7.5(0.9)$ \\
\hline Night & - & - & 8.9 (1.9) & - & - & $7.5(0.8)$ \\
\hline
\end{tabular}

$\mathrm{CGI}=$ chronic gastrointestinal ischemia; $\mathrm{PCO}_{2}=$ carbon dioxide in kilopascal; $\mathrm{B}=$ breakfast, $\mathrm{D}=$ dinner, $\mathrm{CS}=$ compound solution meal; ${ }^{\mathrm{a}} P=0.02,{ }^{\mathrm{b}} P=0.005,{ }^{\mathrm{c}} P=0.04,{ }^{\mathrm{d}} P=0.03$ 
Table 4 Results of different tests compared to final diagnosis

\begin{tabular}{lllll}
\hline Patients & Final diagnosis & GET & 24-h tonometry & Combination GET-24-h tonometry \\
\hline CGI & 17 & $14(82 \%)$ & $13(76 \%)$ & $17(100 \%)$ \\
No ischemia & 16 & $11(69 \%)$ & $15(94 \%)$ & $16(100 \%)$ \\
\hline
\end{tabular}

Data presented as number of patients with positive predictive value (PPV) and negative predictive value $(\mathrm{NPV})$; GET $=$ gastric exercise tonometry; CGI $=$ chronic gastrointestinal ischemia; GET $=$ gastric exercise tonometry

\section{Discussion}

The results of this retrospective study indicate that $24-\mathrm{h}$ gastrojejunal tonometry is feasible and may be clinically useful in diagnosing chronic gastrointestinal ischemia. The measurements were easy to perform, generally well tolerated and no complications occurred.

The fasting baseline $\mathrm{PCO}_{2}$ in both stomach and jejunum was significantly higher in the ischemic patients group compared to the non-ischemic patients. This difference might be explained by the continuous compromised arterial blood flow of the mucosa of the stomach (and/or jejunum) in the ischemic patients group. The significant higher maximum peak after the breakfast and dinner and the borderline significant higher peak after the compound solution meal $(P=0.07$ and 0.052 for stomach and jejunum, respectively) support the theory that, with a maximal metabolic oxygen demand, mucosal ischemia is apparent and detectable using tonometry.

Using the cut-off values predicted by the previously performed healthy subjects study, the positive predictive value of 24-h tonometry seems very promising [14]. Comparing the results of detection of ischemia for 24-h tonometry and GET, no significant differences were found. Theoretically it might be expected that 24-h tonometry is more accurate in patients with postprandial complaints, and GET in patients with exercise-predominant complaints, but this was not found in this small patient series. In five patients the results of GET were incorrect (four false-positive and one false-negative result), whereas the 24-h tonometry (retrospectively) correctly predicted the presence (one patient) or absence (four patients) of gastrointestinal ischemia in these patients.

One of the major advantages of 24-h tonometry over GET is the fact that all patients are suitable for 24-h tonometry, in contrast to GET, where patients have to perform submaximal exercise, which is not always possible due to age, concomitant disease, and/or compromised general condition of the patient. Another advantage of the 24-h tonometry is the familiarity with 24-h $\mathrm{pH}$ measurement, which is a widely accepted diagnostic tool in gastroenterology. Moreover 24-h tonometry testing is more easily standardized than GET, especially regarding the level of exercise, which is difficult to manage and may cause false positive findings during or after excessive exercise [15]. In this study, the $24 \mathrm{~h}$ tonometry was not repeated in a standard fashion after treatment. In two patients who had successful, anatomical and clinical, revascularization 24-h tonometry was repeated, and showed normalization in both patients.

In theory, the compound solution meal (low volume, high calorie content) should be the ideal test meal for provocation of gastrointestinal ischemia. The use of standard meals with large metabolic demand, like the compound solution meal, called for a dose reduction in several patients. These patients already had severely impaired food intake and could hardly tolerate (larger) meals. This dose reduction might have influenced the outcome of the 24-h tonometry, the borderline significant differences between CGI and non-ischemic patients after compound solution meals might be explained by this effect. The results of tonometry after meals have to be interpreted with care. Unsuccessful suppression of acid production and meal-related production of $\mathrm{CO}_{2}$ may influence the results of tonometry. Using optimal acid suppression medication and standardized meals, these effects can be minimized, but not completely ruled out. In this study gastric $\mathrm{pH}$ measurement was used to control acid suppression. Furthermore, duodenogastric reflux of jejunal contents and/or pancreatic juices are quite common and might theoretically influence intragastric and -jejunal $\mathrm{PCO}_{2}$ levels in a major way, leading to false positive tonometry findings [16].

In conclusion, this retrospective study shows that 24-h tonometry is feasible, safe, and has a very promising diagnostic accuracy for the detection of gastrointestinal ischemia. Using high-dose PPI acid suppression and standard meals, and previously established normal values, 24-h tonometry identifies gastrointestinal ischemia with an acceptable accuracy. The definitive role of 24-h tonometry in the diagnosis of chronic gastrointestinal ischemia has to be established in (future) prospective studies.

Acknowledgements We would like to thank Job van der Palen for his advice on statistical matters. We express our thanks to Anja Goossens-Bosch and Anneke Maaskant for their excellent organizing work and guidance of patients. 


\section{References}

1. Derrick JR, Pollard HS, Moore RM (1959) The pattern of arteriosclerotic narrowing of the celiac and superior mesenteric arteries. Ann Surg 149:684-689

2. Bron KM, Redman HC (1969) Splanchnic artery stenosis and occlusion: incidence, arteriographic and clinical manifestations. Radiology 92:323-328

3. Croft RJ, Menon GP, Marston A (1981) Does intestinal angina exist? A critical study of obstructed visceral arteries. Br J Surg 68:316-318

4. Groeneveld ABJ, Kolkman JJ (1994) Splanchnic tonometry: a review of physiology, methodology and clinical applications. J Crit Care 9:198-210

5. Boley SJ, Brandt LJ, Veith FJ, Kosches D, Sales C (1991) A new provocative test for chronic mesenterial ischemia. Am J Gastroenterol 86:888-891

6. Kolkman JJ, Groeneveld ABJ, van der Berg FG, Rauwerda JA, Meuwissen SGl (1999) Increased gastric $\mathrm{PCO}_{2}$ during exercise is indicative of gastric ischaemia: a tonometric study. Gut 44:163167

7. Kolkman JJ, Otte JA, Groeneveld AB (2000) Gastrointestinal luminal $\mathrm{PCO}_{2}$ tonometry: an update on physiology, methodlogy and clinical applications $\mathrm{Br} \mathrm{J}$ Anaesth 84:74-86

8. Otte JA, Geelkerken RH, Oostveen E, Mensink PB, Huisman AB, Kolkman JJ (2005) Clinical impact of gastric exercise tonometry on diagnosis and management of chronic gastrointestinal ischemia. Clin Gastroenterol Hepatol 3:660-666

9. Mensink PB, van Petersen AS, Geelkerken RH, Otte JA, Huisman AB, Kolkman JJ (2006) Clinical significance of splanchnic artery stenosis. Br J Surg 93:1377-1382

10. Poole JW, Sammartano RJ, Boley SJ (1987) Hemodynamic basis of the pain of chronic mesenteric ischemia. Am J Surg 153:171176

11. Fiddian-Green RG (1992) Provocative test for chronic mesenteric ischemia. Am J Gastroenterol 87:543

12. Geelkerken RH, Schultze Kool LJ, Hermans J, Zarza MT, van Bockel JH (1997) Chronic splanchnic ischaemia: is tonometry a useful test? Eur J Surg 163:115-121

13. Kolkman JJ, Groeneveld AB, Meuwissen SG (1999) Effect of gastric feeding on intragastric $\mathrm{PCO}_{2}$ tonometry in healthy volunteers. J Crit Care 14:34-38

14. Mensink PB, Geelkerken RH, Huisman AB, Kuipers EJ, Kolkman JJ (2006) Effect of various test meals on gastric and jejunal carbon dioxide: a study in healthy subjects. Scand J Gastroenterol 41:1290-1298

15. Otte JA, Oostveen E, Geelkerken RH, Groeneveld AB, Kolkman JJ (2001) Exercise induces gastric ischemia in healthy volunteers: a tonometry study. J Appl Physiol 91:866-871

16. Girelli CM, Cuvello P, Limido E, Rocca F (1996) Duodenogastric reflux: an update. Am J Gastroenterol 91:648-653 